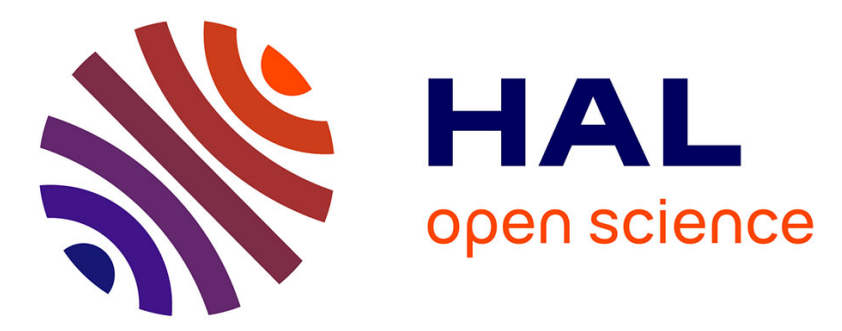

\title{
Plain water jet cleaning of titanium alloy after abrasive water jet milling: Surface contamination and quality analysis in the context of maintenance
}

Xavier Sourd, Redouane Zitoune, Akshay Hejjaji, Mehdi Salem, Anis Hor, Damien Lamouche

\section{To cite this version:}

Xavier Sourd, Redouane Zitoune, Akshay Hejjaji, Mehdi Salem, Anis Hor, et al.. Plain water jet cleaning of titanium alloy after abrasive water jet milling: Surface contamination and quality analysis in the context of maintenance. Wear, 2021, 477, pp.1-13/203833. 10.1016/j.wear.2021.203833 . hal03199552

\section{HAL Id: hal-03199552 https://imt-mines-albi.hal.science/hal-03199552}

Submitted on 7 May 2021

HAL is a multi-disciplinary open access archive for the deposit and dissemination of scientific research documents, whether they are published or not. The documents may come from teaching and research institutions in France or abroad, or from public or private research centers.
L'archive ouverte pluridisciplinaire HAL, est destinée au dépôt et à la diffusion de documents scientifiques de niveau recherche, publiés ou non, émanant des établissements d'enseignement et de recherche français ou étrangers, des laboratoires publics ou privés. 


\title{
Plain water jet cleaning of titanium alloy after abrasive water jet milling: Surface contamination and quality analysis in the context of maintenance
}

\author{
X. Sourd ${ }^{a, b, *}$, R. Zitoune ${ }^{a, * *}$, A. Hejjaji ${ }^{a}$, M. Salem ${ }^{c}$, A. Hor ${ }^{d}$, D. Lamouche ${ }^{b}$ \\ a Institut Clément Ader, CNRS UMR 5312, Université Paul Sabatier, 3 Rue Caroline Aigle, 31400, Toulouse, France \\ ${ }^{\mathrm{b}}$ Safran Aircraft Engines (Villaroche), Rond-point René Ravaud, 77550, Moissy-Cramayel, France \\ ${ }^{\mathrm{c}}$ Institut Clément Ader, CNRS UMR 5312, Campus Jarlard, 81013, Albi, France \\ ${ }^{\mathrm{d}}$ Institut Clément Ader, CNRS UMR 5312, ISAE-SUPAERO, 3 rue Caroline Aigle, 31400, Toulouse, France
}

Keywords:

Abrasive jet cutting

Surface topography

Surface analysis

Profilometry

\begin{abstract}
A B S T R A C T
Abrasive water jet (AWJ) milling process, though being an effective alternative to conventional machining for difficult-to-machine materials, induces abrasive embedment which is an issue for repair application by structural bonding. In this context, the effectiveness of cleaning Ti6Al4V specimens by Plain Water Jet (PWJ) post AWJ milling is studied. For this, Ti6Al4V specimens are milled by AWJ process with varying parameters to create several levels of surface quality and contamination. Different characterization techniques have been used to perform a multi-scale analysis of the machined surfaces and surface quality has been quantified by an innovative criterion called "crater volume" (Cv). Then the specimens are subjected to PWJ cleaning operation (using a single set of parameters chosen after preliminary study). Finally, surface texture analysis and contamination quantification is performed and compared with the AWJ milled surfaces. The results revealed that PWJ cleaning reduced the surface contamination by $65 \%$ without any significant change in $\mathrm{Cv}$, surface texture and topology. However, it was found that it was impossible to dislodge deeply embedded particles. The comparison of pre and post-cleaning contamination levels also revealed that PWJ cleaning process efficiency depends on the AWJ milling parameters (mainly pressure).
\end{abstract}

\section{Introduction}

Titanium alloys (and more especially Ti6Al4V) are widely used in the aerospace industry for their good strength to weight ratio, their high thermal and corrosion resistance as well as their chemical inertness when combined with composite materials. This is particularly the case for the LEAP engine, developed by Safran Aircraft Engines, using fan blades made of 3D interlock woven CFRP composite, with an adhesively bonded leading edge made of Ti6Al4V titanium alloy. Nevertheless, these materials, constitutive of the fan blade, are difficult to machine, which makes their repair a challenging task. For example, in case of bonging issues of the composite fan blade on the titanium leading edge, it can be interesting, for economic reason, to remove the composite part while obtaining a clean titanium surface ready to be bounded with another fan blade. In another case, the titanium leading edge is prone to erosion during service, which implies its complete removal from the composite fan blade. Generally, aircraft manufacturers perform such maintenance operations by removing the damaged area using conventional milling. However, this machining method presents several crippling drawbacks. Indeed, the contact between the cutting tool and the titanium alloy workpiece, which is a difficult to machine material, induces three main issues. Firstly, it leads to premature tool wear due to the low thermal conductivity of the titanium. Hence, the frequent changing of the machining tool drastically increases the price of the repair operation. Secondly, this contact generates high machining temperatures which can modify the microstructure of the material in the vicinity of the heat affected zones. Thirdly, it generates significantly high cutting forces which justify the usage of fixtures with important clamping forces applied on the workpiece during milling. Nonetheless, in case of machining of parts with complex shapes, this fixation operation may be challenging. These cutting forces can also modify the crystallographic texture of the workpiece in the vicinity of the machined surface. Moreover, conventional machining removes material at a constant distance from a reference plane, which forces companies to invest

\footnotetext{
* Corresponding author. Institut Clément Ader, CNRS UMR 5312, Université Paul Sabatier, 3 Rue Caroline Aigle, 31400 , Toulouse, France.

$* *$ Corresponding author.

E-mail addresses: xavier.sourd@iut-tlse3.fr (X. Sourd), redouane.zitoune@iut-tlse3.fr (R. Zitoune).
} 
in expensive Computer Numerical Control (CNC) machines to mill structures with complex shapes. Because of these issues, nonconventional techniques have been considered in order to perform blind-machining repair operations, such as laser beam, electrical discharge and chemical machining. However, all these processes are not suitable alternatives to conventional milling from the industrial point of view. In fact, they are characterized by a rather low Material Removal Rate (MRR) which is an issue when machining time is of primary concern. Moreover, these machining techniques require high setup and operation costs such as machines, tools or highly skilled operators. In addition, in case of chemical machining, the use highly corrosive products makes this machining process non-environmentally friendly [1]. From these considerations, Abrasive Water Jet (AWJ) machining process appears to be a good contender to replace the conventional milling technique for repair application. Indeed, as the 'machining tool' is a jet made of a mix of abrasive particles and water, no excessive machining forces are recorded during milling, avoiding the necessity of firm clamping of the workpiece. In addition, as the jet contains water, the extent of heat affected zones induced by machining is reduced. Besides, contrary to conventional milling process, AWJ machining permits to remove an almost constant depth of cut from the top surface of the workpiece [2]. This specific feature eases the machining of structures characterized by complex shapes. Finally, Abrasive Water Jet machining is a more interesting process from the environmental point of view, as all the contaminants (abrasive particles and chips mainly) are trapped inside the water tank located under the machining table. By filtrating the contaminated water, it is possible to remove the majority of these pollutants. However, despite the numerous advantages of the AWJ milling process over other non-conventional or conventional machining techniques, some specific characteristics of the Abrasive Water Jet process have to be investigated to perform material removal with acceptable geometric precision and surface quality while maintaining the integrity of the material.

Based on several studies focusing on abrasive water jet machining of Ti6Al4V [3-7], though a large set of machining parameters affects the depth of cut, the water pressure, the traverse speed and the scan step (in order of importance), are identified as the most influential. When the water pressure increases, the amount of energy transferred from the jet to the abrasive particles increases too. The more energy they have, the harsher the erosion, hence the deeper the material removal. The opposite trend is observed with the traverse speed: as this parameter increases, the interaction time between the jet and the workpiece decreases, hence reducing the material removal rate. Likewise, an increase in scan step reduces the overlapping area - i.e. the area of material which is milled twice - hence limiting the depth of cut. Though a specific cutting depth can be reached by many combinations of machining parameters, the generated topologies vary with the choice of the parameters set. In fact, as for every machining process, water jet milling generates specific types of defects and damage on the machined surface. In case of Plain Water Jet (PWJ) machining, i.e. without abrasive particles, these defects and damage are in form of cracks. Like the material removal features, the milled surface quality depends on the selected machining parameters. In this context, an increase in water pressure and/or a decrease in traverse speed lead to a multiplication of the generated cracks. These cracks are at first located along the grain boundaries, then spreading inside the grain as the machining conditions become harsher. The number of cracks increases, which helps the formation of a network of cracks and their connexion provokes the removal of the complete grain and produces textured surfaces $[8,9]$. The introduction of abrasive particles within the jet accentuates the surface texturing, which is piloted by the traverse speed when performing normal machining [10]. In addition, the abrasive particles generate other kinds of defects in form of craters. In order to describe the quality of the machined surfaces, indicators such as arithmetic mean roughness (Ra) and waviness (Wa) have been developed for metallic materials. Many researchers concluded that both these parameters depend on complex combinations of several machining parameters such as the stand-off distance [6], the abrasive particles size [11,12] or the impingement angle [12]. However, the analysis of the literature has highlighted the prime influence of the water pressure and the traverse speed of the cutting head on the morphology of the machined surfaces $[12,13]$. As the water pressure, hence the jet speed, increases, the kinetic energy transferred from the water to the abrasive particles increases as well, which induces harsher erosion and poor surface quality. Likewise, when machining with a low traverse speed, more particles hit the surface in a certain amount of time than is case of faster machining, reducing the surface quality. As the evolutions of the MRR and the surface quality with respect to the main abrasive water jet machining parameters are in opposition, the choice of the machining conditions has to be well thought out in the early stage of machining [6,12,14]. The other main additional issue consecutive to the introduction of abrasive particles inside the water stream is in form of embedded grits within the machined material. The degree of contamination also depends on the machining parameters, increasing with an increase in pressure or traverse speed as shown by several authors [10-12]. This contamination can lead to the degradation of the mechanical properties of the machined structures - as the embedded particles acting like stress concentration factors - as well as an important issue for bounding application - as the subtracts have to be clean and free from any contaminants. Researchers have proposed various solutions in order to reduce grit embedment. Fowler et al. [10] have shown that inclining the jet up to $45^{\circ}$ and performing backward milling with a low traverse speed permits to reduce the contaminated surface from $40 \%$ of the total machined surface to $5 \%$. Indeed, the grits bounce from the surface and are expelled from the pocket rather than pushed on the pocket walls. Except this machining method, all the solutions to reduce the contamination by abrasive particles are performed after AWJ machining. Ultrasound cleaning, though being a common technique to reduce grit embedment, has a limited effect when dealing with deeply submerged abrasive particles [15-17]. In this case, an additional PWJ cleaning operation can be considered. However, though suggested by Hashish [18] many years ago, a limited number of studies [19,20] have been carried out in order to analyse the effect of this cleaning process on the degree of contamination and the generated changes in surface quality. Moreover, Huang et al. [19] used this technique in order to remove alpha case phase from titanium alloy with very little abrasive contamination, letting the topic of PWJ as a cleaning technique for abrasive contamination rather unexplored.

The goal of this study is to analyse the influence of Plain Water Jet (PWJ) cleaning on the modification of the textured surface and the contamination rate of aerospace grade titanium alloy Ti6Al4V induced by Abrasive Water Jet (AWJ) milling as well as the microstructure modification. To reach this objective, the influence of the three most significant AWJ milling parameters (viz. water pressure, traverse speed and scan step according to [21]) has been used. First, the depth of cut, surface quality and contamination rate are measured on the milled specimens after the AWJ machining operation based on multiple surface characterization methods (SEM, optical profilometer) and post processing image techniques. Then, the influence of the machining parameters on these features has been analysed. A novel surface quality indicator, called "crater volume" and proposed by Hejjaji et al. [22,23] when performing AWJ milling of composite materials, is used in this study in order to quantify the surface quality of the milled titanium specimens. After the milling phase, the specimens are cleaned by an additional PWJ cleaning operation with set parameters obtained after preliminary study. Finally, an analysis of the modifications induced by the cleaning process in the milled depth, crater volume and degree of contamination is performed. 


\section{Material and methods}

\subsection{Material}

The material used in this study is Ti6Al4V titanium alloy which is an aerospace grade material widely used in the aircraft engine components. In order to analyse the influence of fundamental AWJ process parameters (viz. water pressure, traverse speed and scan step), Ti6Al4V specimens were milled. A Ti6Al4V titanium alloy mother plate having a uniform thickness of $3 \mathrm{~mm}$ was used to obtain 36 specimens $(140 \mathrm{~mm} \times$ $20 \mathrm{~mm}$ ) which have been cut by AWJ. For each specimen, three identical pockets, of size $20 \mathrm{~mm} \times 20 \mathrm{~mm}$, have been milled by AWJ process in order to study the repeatability of the results.

\subsection{Experimental set up}

The specimen preparation by cutting and the machining experiments were performed with the same AWJ machine 'Flow Mach 4c' manufactured by Flow International Corporation. For the abrasive particles, Arabian garnet sand in size of 120 mesh supplied by Garnet Arabia Company Ltd (Saudi Arabia) was used for specimen preparation by cutting as well as milling experiments. The specimens were cut from the same mother plate using standard AWJ machining parameters recommended by the AWJ machine manufacturers. However, for milling experiments, the machining parameters varied at different levels to produce specimens with diverse surface quality and degree of damage in order to study the influence of machining parameters on these features. AWJ machining involves a long list of variable machining parameters (cf. Table 1), for this study only three variables were considered viz. water pressure, jet traverse speed and scan step. Majority of the other parameters were fixed for economic reasons as changing those parameters would require extra time and equipment, which will be not practical in an industrial environment. For instance, single size of abrasive grit was used for all the milling experiments due to limitation of the AWJ machine (only one abrasive feeding system available).

The selection of values of the variable parameters was based on the literature review on AWJ milling [1,3-7,12]. As the water pressure is the most important parameter influencing the machined surface quality [3, $4,6,12$ ], four levels were considered for the experiments. It is important to mention that a change in final effective water pressure during milling was noticed with respect to the input pressure. This variation, occurring as the jet exits the nozzle, is estimated between 9 and $18 \mathrm{MPa}$, depending on the input pressure. For analysis and calculation purposes, the effective value of the pressure is considered and referred as "water pressure", as seen in Table 1. For both traverse speed and scan step, three levels were considered (cf. Table 1 ). In addition, the value of abrasive flow rate (AFR) was fixed at $0.18 \mathrm{~kg} / \mathrm{min}$, following the work of Cénac et al. [24], in order to maximise the material removal rate with the available cutting head, optimization being of primary concern in the industrial context. Also, a fixed standoff distance (SoD) was considered based on the fact that its influence on material removal was way inferior than the

Table 1

Set and variable parameters selected for the milling process.

\begin{tabular}{|c|c|c|c|}
\hline \multicolumn{2}{|l|}{ Set parameters } & \multicolumn{2}{|l|}{ Variable parameters } \\
\hline Parameter & Value & Parameter & Levels \\
\hline $\begin{array}{l}\text { Focusing tube } \\
\text { diameter }\end{array}$ & $1.016 \mathrm{~mm}$ & Pressure P (MPa) & $\begin{array}{l}118 / 157 / 214 / \\
249\end{array}$ \\
\hline Focusing tube length & $76 \mathrm{~mm}$ & & \\
\hline Nozzle diameter & $0.3302 \mathrm{~mm}$ & & \\
\hline Type of abrasive & $\begin{array}{l}\text { Garnet } \\
\text { sand }\end{array}$ & $\begin{array}{l}\text { Traverse speed V (m/ } \\
\text { min) }\end{array}$ & $1 / 2 / 4$ \\
\hline Abrasive size & \#120 & & \\
\hline Abrasive flow rate & $\begin{array}{l}0.18 \mathrm{~kg} / \\
\min \end{array}$ & Scan step SS (mm) & $0.5 / 1.0 / 1.5$ \\
\hline Standoff distance & $100 \mathrm{~mm}$ & & \\
\hline
\end{tabular}

influence of the selected variable parameters. The SoD was set at 100 $\mathrm{mm}$, which is a value close to the ones used by other authors [24-26] in case of machining with PWJ and AWJ. The experiments were based on a full factorial design (36 specimens) and were repeated three times for each combination, leading to a total of 108 milled pockets.

In order to avoid any movement of the specimens due to water swirl during the machining operations, they were maintained on the machining table by screws (cf. Fig. 1a). The pockets were achieved by adopting a raster scan pattern as pocket milling path strategy as show in Fig. 1b. The milling path was extended beyond the ends of the specimen in order to provide enough distance for the stabilisation of the traverse speed after direction changes. This additional distance ensures that the pocked is milled at the intended traverse speed and the possible error caused by unstable traverse speeds (during acceleration or deceleration when changing direction) is eliminated.

As already mentioned in section 1 , several studies concerning AWJ milling [10-12,15] have ascertained that the milled surfaces are contaminated by the embedment of the abrasive particles used with water. In order to reduce this contamination, an additional cleaning operation consecutive to the AWJ milling was proposed for many years by Hashish [18]. However, the cleaning procedure has rarely been applied or studied $[19,20]$. In this context a successive cleaning operation has been performed in this study on the AWJ milled specimens using the same AWJ machine but without introducing abrasive particles in the water jet (Plain Water Jet). A preliminary study has been conducted in order to select the cleaning parameters (viz. water pressure, traverse speed and scan step). The objective was to maximise the contamination removal without reducing the amplitude of the residual stress at the vicinity of the machined surfaces. The selected cleaning parameters are presented in Table 2 and the cleaning path strategy is the same as the one used for milling. At last, whatever the operations performed (milling/cleaning), all the pockets have been subjected to cleaning by pressurized air after the milling/cleaning operations to remove the loose contaminants and dry the water.

\subsection{Characterization methods}

\subsubsection{Machined surfaces and defects characterization}

The topographies of the milled surfaces were characterized using optical profilometer Infinite Focus SL from Alicona (cf Fig. 2). The equipment employs a technique called focus variation to digitally recreate the topography from the coordinates of each pixel centre of the scanned area acquired by autofocusing the optics along the device's optical axis. The parameters set for the topography acquisition is summarised in Table 3. These selected parameters provide an acceptable precision of $0.4 \mu \mathrm{m}$ in height ( $\mathrm{Z}$ axis) and inferior to $8 \mu \mathrm{m}$ across the surface ( $\mathrm{X}$ and $\mathrm{Y}$ axis) without compromising the time taken for acquisition ( $22 \mathrm{~min}$ for $282 \mathrm{~mm}^{2}$ ). The acquired topographies, having an area of $282 \mathrm{~mm}^{2}(16.8 \times 16.8 \mathrm{~mm})$, were used to quantify the machining induced damage by calculating the parameter called "crater volume" $(\mathrm{Cv})$. This parameter represents the average volume of craters produced during milling i.e. the volume between the least squares plane (mid plane of the surface) and the bottom surface. The acquired topography data set was straightened using the software provided by the manufacturer of the optical profilometer to avoid erroneous calculations. This technique was proposed by Hejjaji et al. [22,23] when machining composite materials and has proven to be a good estimator of the post-machining surface quality, especially for AWJ milled surfaces. The topographical calculation of $\mathrm{Cv}$ was made on a representative area of $196 \mathrm{~mm}^{2}(14 \mathrm{~mm} \times 14 \mathrm{~mm})$. Though the scanned area was larger (282 $\mathrm{mm}^{2}$ ), only $196 \mathrm{~mm}^{2}$ were considered for calculations to avoid the edge effects. Finally, the obtained $\mathrm{Cv}$ was normalised as volume per unit area $\left(\mathrm{mm}^{3} / \mathrm{cm}^{2}\right)$ which facilitates better comparison between the different machined specimens.

Scanning Electron Microscope (SEM) in Secondary Electron (SE) mode was used to find and identify various machining induced defects 


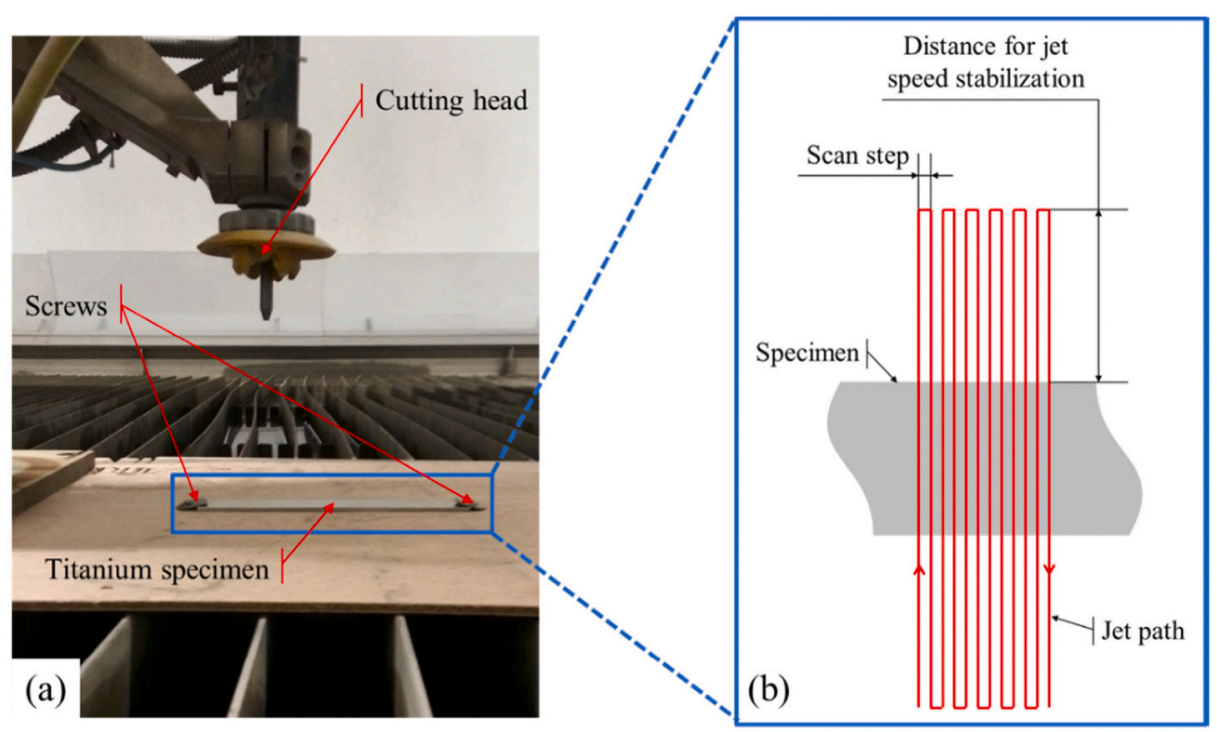

Fig. 1. (a) Set up of the machining operations and (b) Schematic top view of the milling path strategy.

Table 2

Set parameters selected for the cleaning process.

\begin{tabular}{ll}
\hline Parameter & Value \\
\hline Standoff distance & $100 \mathrm{~mm}$ \\
Cleaning pressure & $254 \mathrm{MPa}$ \\
Traverse speed & $2 \mathrm{~m} / \mathrm{min}$ \\
Scan step & $1 \mathrm{~mm}$ \\
\hline
\end{tabular}

on the milled surfaces (cf. Fig. 3). In addition, Back Scattered Electron (BSE) images were also acquired (over a total surface of $5 \mathrm{~mm} \times 5 \mathrm{~mm}$ ) in order to quantify the surface contamination caused by the abrasive particle embedment. The BSE sensor differentiates various elements present on the studied surface based on their atomic number and hence produces a grey scale image of the surface where elements with lower atomic numbers are darker and vice versa. Based on this principle, the BSE images were analysed thanks to Aphelion software using the segmentation and threshold tools to determine the area contaminated by the abrasive particles.

\section{Results and discussion}

\subsection{Influence of the milling parameters on material removal}

The first and foremost parameter to study when performing controlled depth milling by AWJ is the milled depth. Unlike conventional machining, where the depth of removed material is mainly piloted by the position of the tool, the milled depth is not as simple to control in case of AWJ milling. In fact, it is the outcome of energy supplied for material removal in the form of AWJ. Hence, it is necessary to identify the machining parameters having an effect on the material removal features, quantify their influence and rank them in order of importance.

Table 3

Parameters used for the profiles and topographies acquisition.

\begin{tabular}{ll}
\hline Parameter & Value \\
\hline Objective & $10 \mathrm{x}$ \\
Vertical resolution $(\mu \mathrm{m})$ & 0.4 \\
Lateral resolution $(\mu \mathrm{m})$ & $<8$ \\
Scanned surface $\left(\mathrm{mm}^{2}\right)$ & $16.8 \times 16.8$ \\
Used surface $\left(\mathrm{mm}^{2}\right)$ & $14.0 \times 14.0$ \\
\hline
\end{tabular}

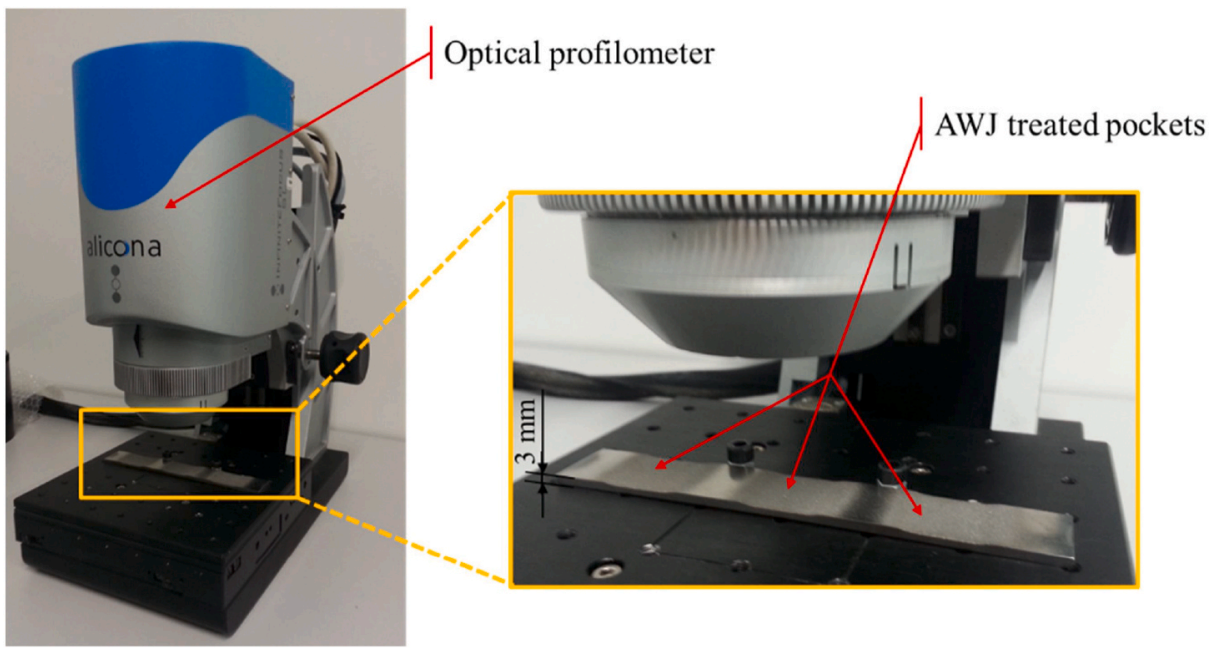

Fig. 2. Optical profilometer used for the topographies acquisition. 


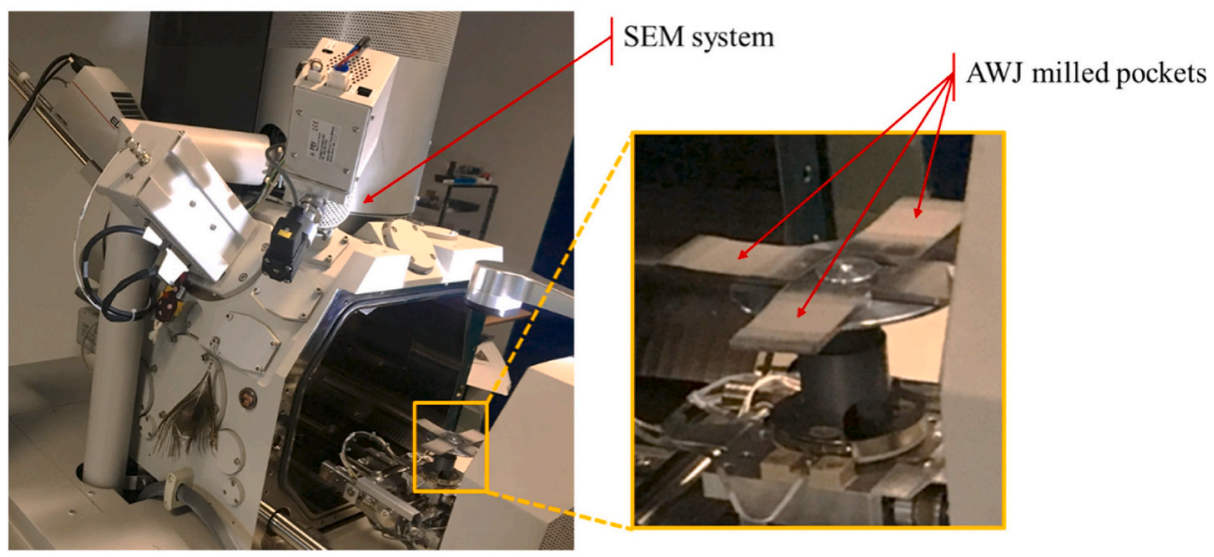

Fig. 3. Scanning Electron Microscope used for the observations of the milled surfaces.

The milling experiments performed clearly indicate the influence of all selected process parameters (pressure, traverse speed and scan step) on the material removal parameters like milled depth and material removal rate (MRR). The mean effect of the milling parameters on the pocket depth (milled depth) is presented in Fig. 4. It is evident that a clear rise is seen in the milled depth with the increase of water pressure (cf. Fig. 4a). For instance, at a traverse speed of $1 \mathrm{~m} / \mathrm{min}$, a rise of pressure from 118 to $249 \mathrm{MPa}$ leads to an increase of the pocket depth by a factor of 2.9 (from 0.42 to $1.21 \mathrm{~mm}$ ). This rise in material removed and hence the higher depth can be explained by the fact that the pressure is linked to the energy of the jet, hence the energy available for the abrasive particles. In fact, the pressure is transformed to the kinetic energy of the jet stream and this energy is conveyed by the abrasive particles. Therefore, higher the water pressure, higher is the kinetic energy and higher the velocity of the abrasive particles impinging on the workpiece surface thereby removing more material. On the contrary, the pocket depth decreases when increasing the traverse speed: for example, with a water pressure of $214 \mathrm{MPa}$, the pocket depth is reduced by a factor of 3.7 (from 0.92 to $0.25 \mathrm{~mm}$ ) when the traverse speed is increased by a factor of 4 (from 1 to $4 \mathrm{~m} / \mathrm{min}$ ). Lower traverse speeds mean more interaction time between the abrasive laden jet and the target surface besides more number of abrasive particles impacting the target surface leading to higher material removal. In addition, the evolution of the pocket depth with the scan step follows the same trend as observed for the traverse speed (cf. Fig. 4b). At a water pressure set to $249 \mathrm{MPa}$, when the scan step is three times higher (from 0.5 to $1.5 \mathrm{~mm}$ ), the milled pocket is 3.9 times shallower (from 1.21 to $0.31 \mathrm{~mm}$ ). This variation is due to the difference in overlapping of adjacent milling paths traced when machining with a low scan step $(0.5 \mathrm{~mm})$ and at high scan steps $(1.5$ $\mathrm{mm}$ ). In fact, jet flow pattern image analysis has shown that the primary jet diameter at the vicinity of the workpiece varies between 1.5 and 2.5 $\mathrm{mm}$ depending on the water pressure at SoD of $100 \mathrm{~mm}$. Therefore, at low scan step of $0.5 \mathrm{~mm}$ the adjacent jet paths overlap each other by $66-80 \%$ depending on the pressure, thereby milling the overlapped area twice, giving rise to higher milled depth. On the contrary, when machining with a scan step of $1.5 \mathrm{~mm}, 0 \%$ (complete isolation) to $40 \%$ overlapping can occur depending on the pressure. Hence, high scan step generates shallow depths owing to the isolation or reduced overlapping of the adjacent jet paths. It can be noted that all the trends are in accordance with previous studies dealing with AWJ machining of Ti6Al4V $[3,7,12]$. Moreover, the repeatability of the results is satisfying, with a maximum standard deviation of $8 \%$ of the depths.

As already known, material removal during AWJ machining is due to the erosion caused by the abrasive particles which inherits energy from the water jet. As seen in the previous paragraph, water pressure is the most influential parameter for the milled depth. However, jet traverse speed and scan step have noticeable influence on the milled depth. It can be noticed that changing traverse speed and scan step will have direct consequences on the machining time. As both of these parameters affect the machining time, Arola et al. [27] introduced a parameter called the "milling intensity" by merging both the traverse speed and the scan step in a single parameter. The milling intensity, noted $\mathrm{I}$ (in $\mathrm{s} / \mathrm{mm}^{2}$ ), is defined as the ratio between the machining time to mill the surface of the specimen and the milled surface, following equation (1), which is equivalent to the inverse of a surface removal rate.

$I=\frac{\frac{\frac{L}{S S} \cdot W}{\frac{1000 \cdot V}{60}}}{L \cdot W}=\frac{60}{1000 \cdot V \cdot S S}$

Where:
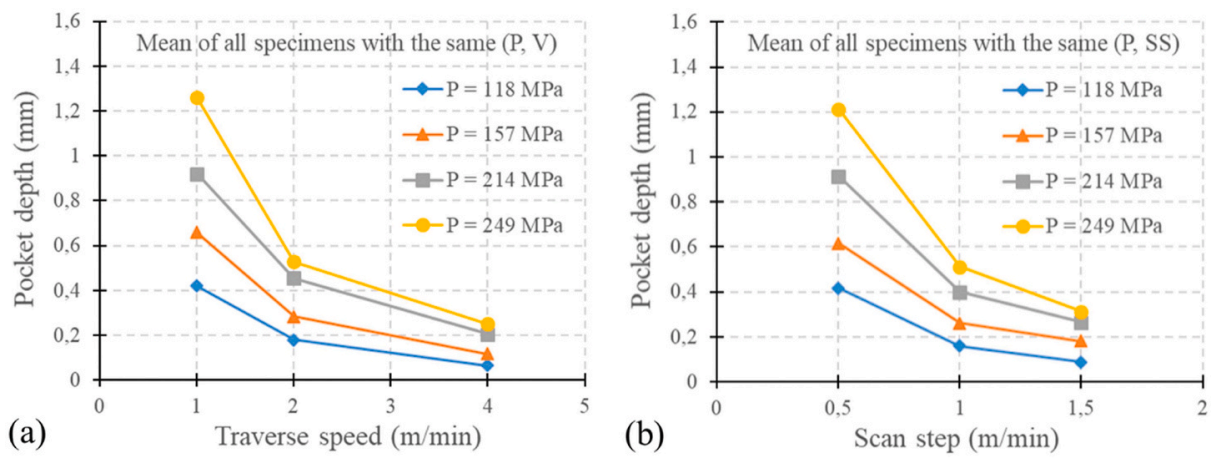

Fig. 4. Influence of the machining parameters on the milling depth. With: (a) Mean effect of the pressure and traverse speed and (b) Mean effect of the scan step and pressure. 
$\mathrm{L}$ and $\mathrm{W}$ represent respectively the length and width of the milled pocket.

$\mathrm{V}$ and SS correspond respectively to the jet traverse speed and the scan step as defined in Table 1.

From Fig. 5a, it can be seen that at low milling intensities the milled depth is also low. In fact, low milling intensity induces high traverse speed or high scan step, meaning that energy interaction between AWJ and the target surface is low and hence the milled depth is small. Good repeatability is obtained for specimens machined with the same milling intensity as shown in Fig. 5b (circled areas). For example, the points, which intensity is $0.03 \mathrm{~s} / \mathrm{mm}^{2}$, correspond to specimens milled with parameter sets $\mathrm{V}=4 \mathrm{~m} / \mathrm{min} / \mathrm{SS}=0.5 \mathrm{~mm}$ and $\mathrm{V}=2 \mathrm{~m} / \mathrm{min} / \mathrm{SS}=1$ $\mathrm{mm}$. The mean difference between each couple of points is less than $8 \%$.

As the "milling intensity" parameter combines both the scan step and the traverse speed which defines the time taken for milling a surface of particular area, it can be used to study the MRR. The milling intensity being equivalent to the inverse of a surface removal rate, the Material Removal Rate is hence given by equation (2).

$M R R=H_{/}$

Where:

$\mathrm{H}$ represents the machined depth.

I corresponds to the machining intensity as defined in equation (1).

Fig. 6 shows the mean effect of the water pressure and intensity on the MRR. It is clear from Fig. 6 that as the water pressure increases, MRR increases too because at higher water pressure the energy available for abrasive particles is high and hence more material is removed. However, a critical behaviour is seen with respect to machining intensity. For example, at a water pressure of $118 \mathrm{MPa}$, MRR of 4.88 and $5.19 \mathrm{~mm}^{3} / \mathrm{s}$ are observed for respective milling intensities of 0.03 and $0.06 \mathrm{~s} / \mathrm{mm}^{2}$, meaning there is no significant change in MRR even when machining intensity is doubled. This suggests that there is a certain level of saturation of MRR for a given water pressure even when longer exposure time is long especially for specimens milled with lower pressures. For instance, for water pressures of $118 \mathrm{MPa}$ and $157 \mathrm{MPa}$ saturation was observed at intensity of $0.04 \mathrm{~s} / \mathrm{mm}^{2}$. However, this critical saturation behaviour diminishes as the water pressure increases suggesting that the saturation limit is a function of the water pressure. Indeed, for a pressure of $214 \mathrm{MPa}$, the saturation phenomenon was noticed at $0.06 \mathrm{~s} / \mathrm{mm}^{2}$ whereas for water pressure of $249 \mathrm{MPa}$ the saturation did not appear in the tested range of values $\left(0.01-0.12 \mathrm{~s} / \mathrm{mm}^{2}\right)$.

\subsection{Types of defects induced by AWJ milling}

The machined surfaces were observed using Scanning Electron Microscope (SEM) to identify various kinds of machining induced defects.

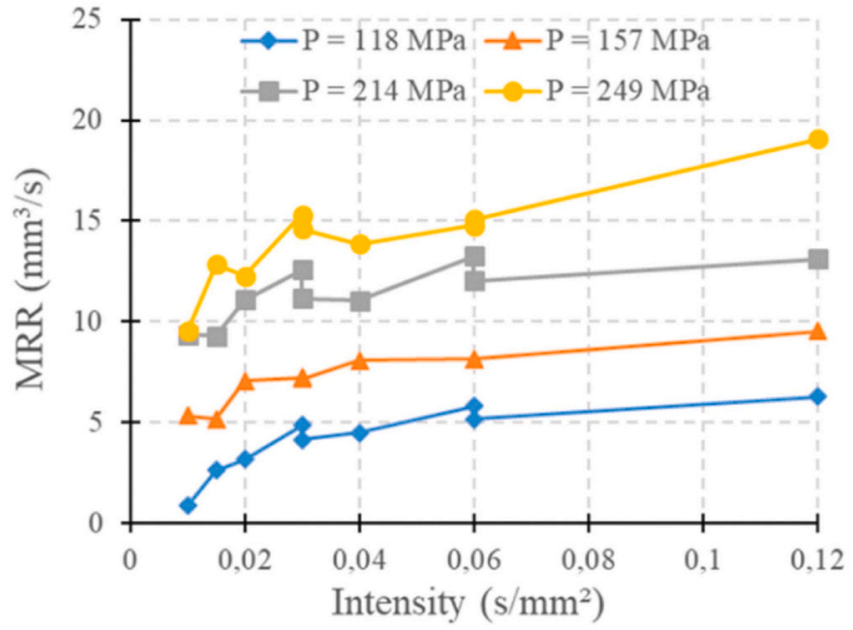

Fig. 6. Mean effect of the pressure and intensity on the Material Removal Rate (MRR)

The first type of defect identified is surface contamination in form of abrasive particle embedment (cf. Fig. 7). The abrasive particles embedment is due to the entrapment of the high velocity abrasive particles impacting the target surface in the plastically deformed zones. The hardness of the abrasive is much higher than the titanium workpiece and hence on high velocity impact the abrasive particles gets embedded in the relatively softer titanium specimen. The SEM images revealed that abrasive particles of various sizes were randomly embedded on the milled surfaces, whatever the selected machining parameters. For instance, Fig. 7a shows a global view of the Titanium surface milled with water pressure of $118 \mathrm{MPa}$, scan step of $0.5 \mathrm{~mm}$ and jet traverse speed of $1 \mathrm{~m} / \mathrm{min}$, clearly depicting abrasive particle (dark grey) contamination. A closer inspection reveals that the embedded abrasives can be classified based on their size viz. grits larger than $100 \mu \mathrm{m}$, grits sized between 25 and $100 \mu \mathrm{m}$ and grits below the size $25 \mu \mathrm{m}$. The large embedded abrasive particles of size greater than $100 \mu \mathrm{m}$ are grits which are very close to their original size $(125 \mu \mathrm{m})$. Even though they are found broken, they are embedded as a single entity. These large grits are either loosely embedded (cf. Fig. 7b) or deeply entrapped (cf. Fig. 7c) in the Titanium workpiece. Abrasive particles of size $25-100 \mu \mathrm{m}$ (cf. Fig. 7d) are most extensively found across the surface. These are mostly grits that were broken in the mixing tube and focusing tube of the AWJ machine or broken after impact and partially washed away by water from secondary jet. Another significant irregularity observed was the presence of titanium burr (thin sections) along the boundary of abrasive particle impact (cf. Fig. 7d). This is caused by the plastic flow of the metal occurring due to the high velocity impact of the abrasive particle. In addition, striations are also found on the surface showing signs of material removal by
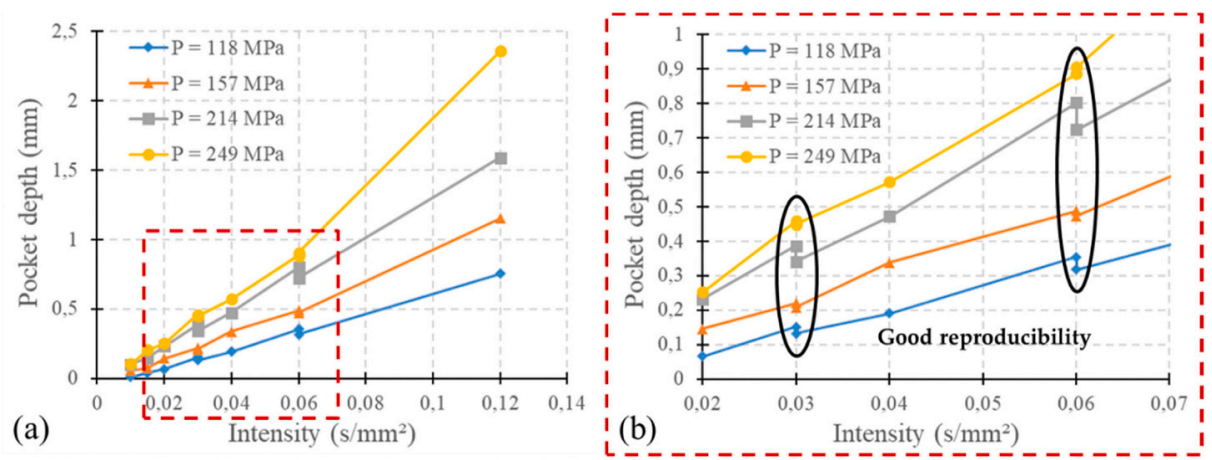

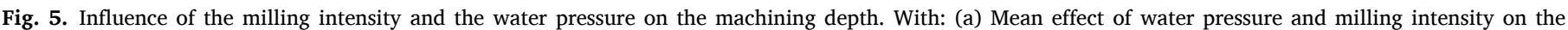
machined depth and (b) zoom in the low intensities area. 

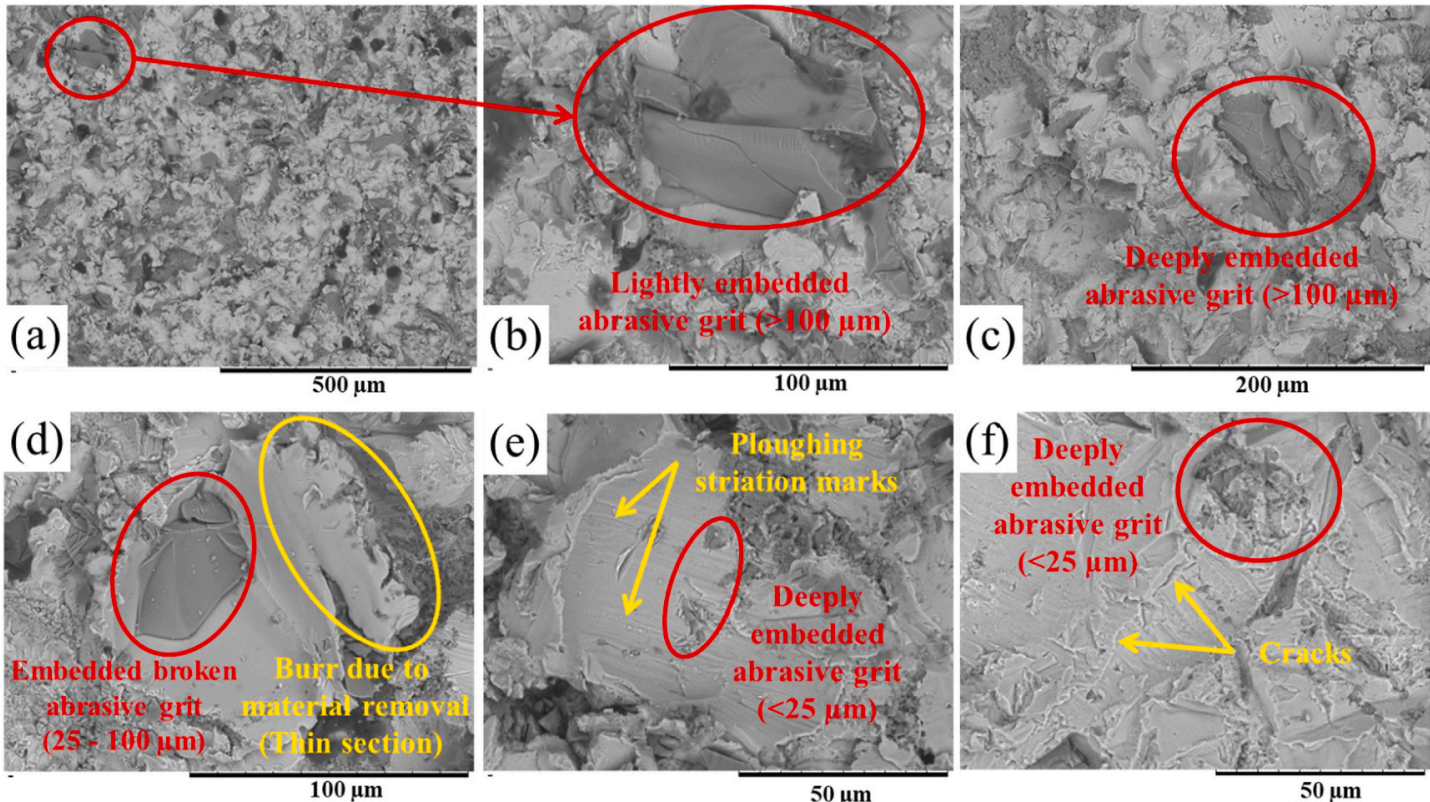

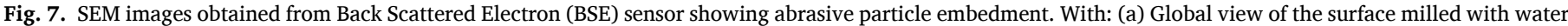

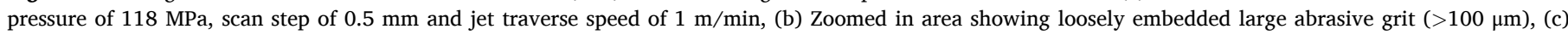

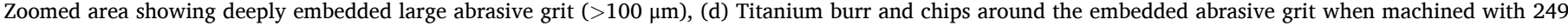
MPa of water pressure, $0.5 \mathrm{~mm}$ of scan step and $4 \mathrm{~m} / \mathrm{min}$ of jet traverse speed, and (e) and (f) Deeply embedded minute broken abrasive grits.

ploughing action of the abrasive particle (cf. Fig. 7e). Moreover, cracks can be found on the machined surfaces (cf. Fig. 7f). They are the consequences of high contact stresses generated by the impact of the abrasive particles at high velocity (several hundreds of $\mathrm{m} / \mathrm{s}$ ). Due to repeated impacts, a web of cracks is formed, leading to the formation of chips as the cracks join. Lastly, microscopic abrasive grits were found deeply embedded in the Titanium surface whose size was less than 25 $\mu \mathrm{m}$ (cf. Fig. 7e and f). These micro particles are formed by breaking of large abrasive particles colliding with each other in the mixing and focusing tube of the AWJ machine. These micro abrasives impact the workpiece surface and get easily embedded owing to their minute size. This abrasive particle embedment can lead to serious discrepancies during service life of the machined specimen, by forming stress concentration zones. Hence, it is necessary to quantify the surface contamination caused by AWJ milling and also find suitable methods to reduce or eliminate this surface contamination.

The second kind of pollutant was organic contaminants (cf. Fig. 8) which was confirmed from the X-Ray diffractometric (XRD) analysis. The tests revealed that these contaminants are mainly constituted of carbon, sodium, calcium. Carbon may be inherited from the alloy whereas sodium and calcium are the constituents of dried salts originated from the water used in AWJ machining. Unlike abrasive particle embedment, occurrence of organic contamination was scarce.

Cartographies of two pockets bottom illustrated in Fig. 9 are obtained by optical profilometry for different sets of machining parameters. It can be easily seen that the choice of the milling parameters has a real impact on the surface quality. Indeed, when milling is conducted with a low water pressure and a high scan step (cf. Fig. 9a), the surface is rather flat with little changes in heights (maximum around $80 \mu \mathrm{m}$ ). Nevertheless, when machining is achieved using a greater water pressure and a smaller scan step (cf. Fig. 9b), the pocket bottom surface is much more rugged (from -100 to $70 \mu \mathrm{m}$ in heights). However, in both cases, the presence of cavities on the milled surface (dark blue zones), which can be termed as craters, are observed. These craters present a random distribution and concern all the specimens, with different extent and depth, no matter the set of parameters used to perform the machining.

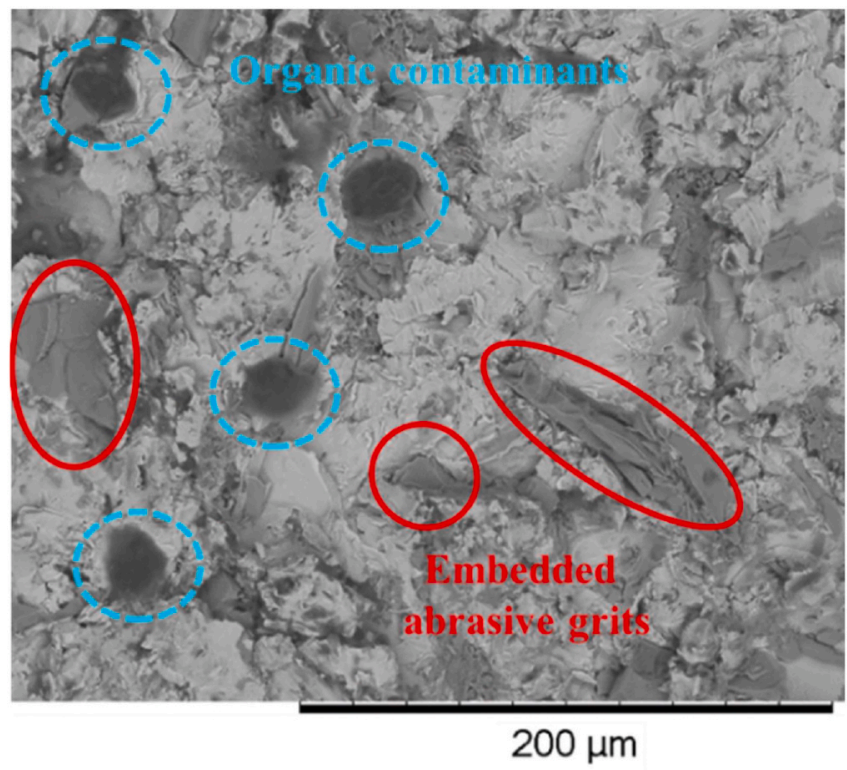

Fig. 8. SEM image obtained from BSE sensor distinguishing between abrasive particles (highlighted by circled zones) and organic contaminants (highlighted by dotted zones) in a specimen machined with water pressure of $118 \mathrm{MPa}$, scan step of $0.5 \mathrm{~mm}$ and jet traverse speed of $1 \mathrm{~m} / \mathrm{min}$.

The presence of these craters is confirmed by the SEM observations (cf. Fig. 10), which revealed two different types of craters. The most common kind of crater formation was by the impact of the abrasive particle (cf. Figs. $7 \mathrm{~d}$ and 10a) where the workpiece material is displaced by the high velocity abrasive particle due to plastic deformation. These craters formed by abrasive impact are often large and deep and are partly filled with left over abrasive embedded inside the crater. The other kind of crater which is smaller and also swallower is created due to ploughing of the workpiece material from the surface by abrasive particles similar to cutting action (cf. Figs. 7e and 10b). These craters are 

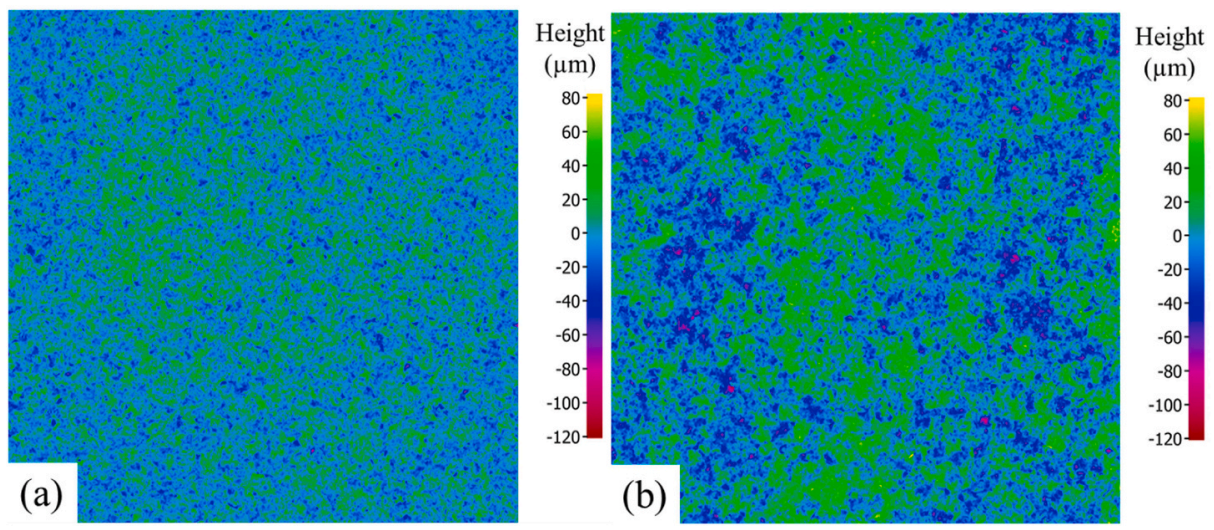

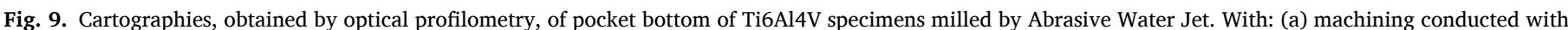

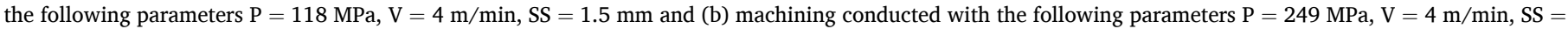
$0.5 \mathrm{~mm}$.
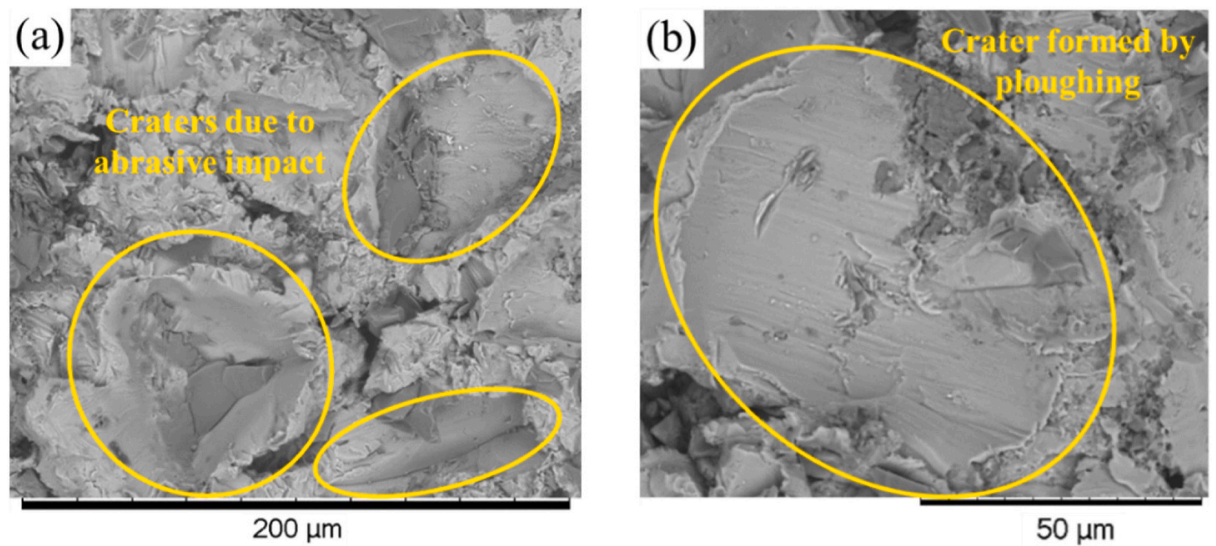

Fig. 10. Craters generated by abrasive particles impact (a) and ploughing (b) consecutive to the AWJ milling process.

clearly distinguishable due to their small and shallow size and also unique striation marks on the crater floor. Overall, the diameter of craters varies in the range of $40 \mu \mathrm{m}-150 \mu \mathrm{m}$. It is important to notice that the abrasive used for the experiments was garnet sand of 120 mesh size which corresponds to a diameter of $125 \mu \mathrm{m}$. Hence, the majority of the craters created by abrasive particle impact were close to this diameter range (80-140 $\mu \mathrm{m})$. However, smaller craters were also observed, which may have been created due to abrasive particles that were broken down to smaller sizes inside the focusing tube due to internal collisions when mixing with water or due to ploughing phenomenon as explained previously. The presence of micro craters was haphazard in all the samples irrespective of machining parameters used and were randomly scattered all over the machined surface. In addition, these microscopic observations revealed that the machining parameters has notable influence on the occurrence of craters, which requires further investigation.

\subsection{Quantification of the surface quality}

The information obtained from the microscopic analysis of the machined surface discloses that the machined surface has a complex texture comprising trapped contaminants and craters. Hence, the machined surface cannot be treated like a surface obtained by conventional machining where the surface quality quantification by surface roughness parameters is satisfactorily adequate. Therefore, a specific approach for surface quality quantification is needed in the case of AWJ milling. Hence, the surface quality is quantified based on types of defects produced by the machining process viz. contamination and mechanical defects (craters).

\subsubsection{Contamination}

The quantification of the machined surface contamination is done by investigating the BSE (Back scattered electron) images obtained from the SEM observations. The grey scale images obtained from the BSE sensor represent the elements with lower atomic numbers with darker pixels and vice versa. Based on this principle, the BSE images were analysed thanks to 'Aphelion' software using the segmentation and threshold tools to determine the area contaminated by the abrasive particles. Fig. 11a shows a sample BSE image analysed for surface contamination using 'Aphelion' software. The pixels contained inside the yellow borders are counted for calculating the degree of contamination as a percentage of the inspected area. The effect of the water pressure and the milling intensity on the degree of contamination is presented in Fig. 11b. It is clearly seen that the milling parameters have least influence on the degree of contamination. However, it is seen that for both milling intensities, the contamination is slightly reduced when the pressure increases. It is because of the fact that, at high water pressure, the secondary jet, which is mostly constituted of water, has more energy and acts as a cleaning jet which removes loosely embedded abrasive particles. However, the reduction is quite low to draw a strong conclusion. Based on these results, it can be established that the amount of abrasive particles embedded within the specimens is likely to be similar whatever the selected milling parameters. However, it is important to note that this method used to quantify the degree of contamination is only a surface measurement and does not take into account the depth of embedment of the abrasive grits. 

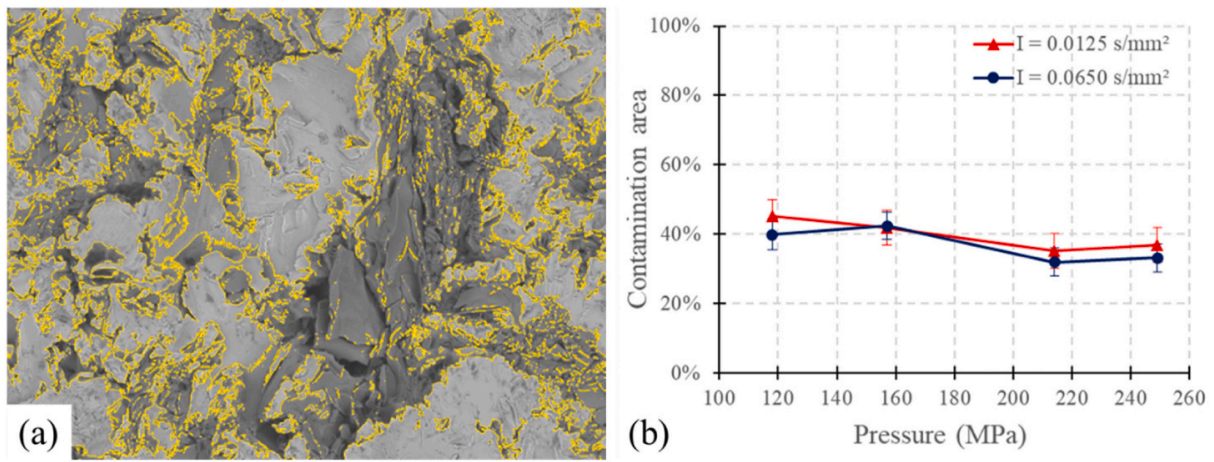

Fig. 11. (a) Selection of pixels representing contaminants including abrasive particles (contained inside yellow borders) after segmentation and threshold process in Aphelion software and (b) Influence of the machining parameters on the degree of contamination. (For interpretation of the references to colour in this figure legend, the reader is referred to the Web version of this article.)

\subsubsection{Mechanical defects}

The SEM observations clearly suggest that the major mechanical defect during AWJ milling of Titanium alloy is present in the form of micro craters. Hence, it is important to quantify them in order to effectively define the machined surface quality. Traditionally, parameters like surface roughness (Ra) are used to qualify machined surface quality. However, they are highly localised measure and seldom represent the important features of the machined surface. Hence, in this study, the major machining induced defect is quantified as crater volume (Cv) to describe the surface quality. Hejjaji et al. [22] first proposed this parameter for AWJ milled CFRP composites. This is, to the authors knowledge, the first use of $\mathrm{Cv}$ as an indicator of post AWJ machining surface quality for metallic materials.

Fig. 12a shows the mean effect of water pressure and traverse speed on the crater volume. It is seen that $\mathrm{Cv}$ is directly proportional to the water pressure and inversely proportional to the traverse speed. The similar trend is observed for the material removal parameter milled depth. In fact, the abrasive particles impinging on the workpiece remove the material by ploughing action which creates the craters. Hence, when the water pressure increases more energy is available for the abrasive particles and hence deeper ploughing action leading to higher crater volume. Nonetheless, as the jet traverse speed increases, a decrease in $\mathrm{Cv}$ is seen. It has to be noted that the abrasive particles emerging from the focusing tube has two components of velocity viz. horizontal and vertical, where vertical velocity is the major component and is responsible for material removal. However, when the jet traverse speed increases, the vertical velocity component is reduced and hence the energy available for material removal is reduced. In addition, at higher traverse speed the jet exposure time reduces, which means the number of abrasive particles targeting the workpiece decreases. Therefore, at high jet traverse speed, fewer and shallower craters are formed, thereby decreasing the Cv. Furthermore, Fig. 12b shows the evolution of Cv with respect to water pressure and milling intensity. It is seen that with increasing milling intensity the crater volume also increases. Higher milling intensity means higher exposure time. As already discussed, the number of abrasive grits hitting the workpiece surface increases when exposure time increases and therefore the creation of craters increases too, thereby raising the crater volume.

In-depth analysis has been conducted on the measurements of the cartographies obtained by optical profilometer. Indeed, 3D surface roughness $\mathrm{Sa}$, initially developed for the machined surface characterization of metallic materials, has been measured. The evolution of this indicator as a function of the three studied process parameters is similar to the one observed for the crater volume $(\mathrm{Cv})$. Indeed, a linear relationship between these two surface quality criteria was noticed (Fig. 13).

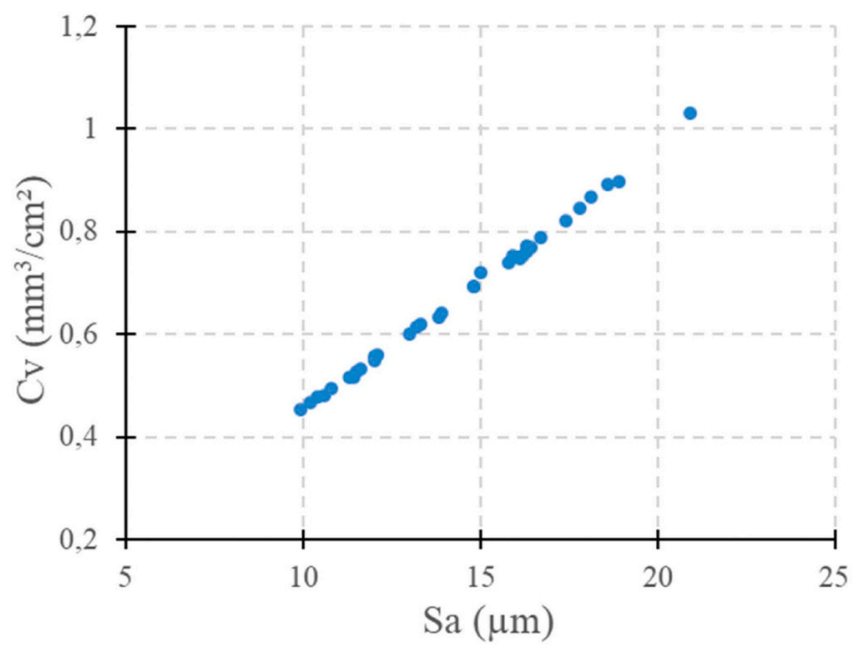

Fig. 13. Evolution of the $\mathrm{Cv}$ in function of Sa for all the machined pockets.
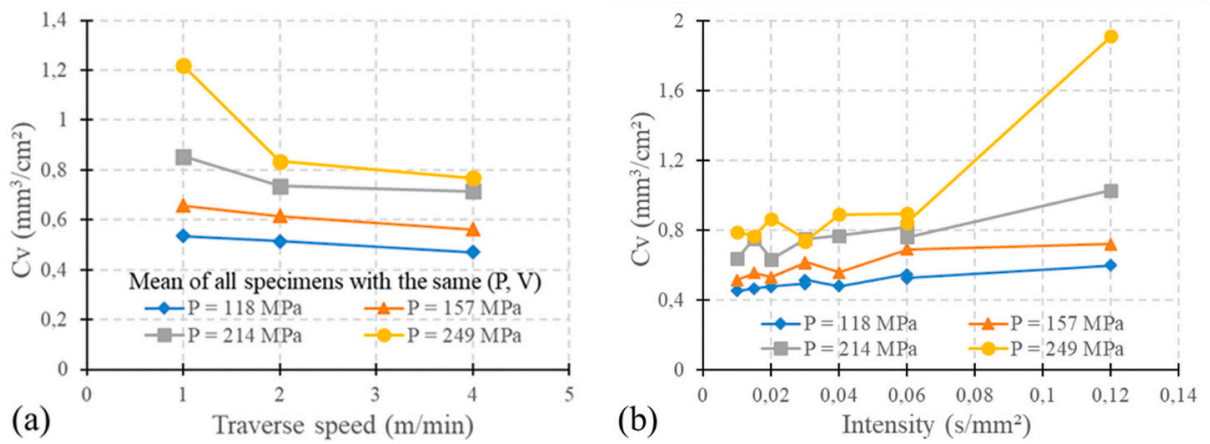

Fig. 12. Mean combined effect of (a) pressure and traverse speed and (b) pressure and machining intensity on the crater volume by unit area $\mathrm{Cv}$. 
From this analysis, $\mathrm{Cv}$ parameter can be used to describe machined surface quality of metallic materials. It is important to mention that several researchers have proven the link between the quality of AWJ machined metallic surfaces defined by classical criteria (such as Sa) and the changes in mechanical behaviour of the machined specimens [13, 14]. However, this relationship is not valid when composite materials are considered. Indeed, Nguyen-Dinh et al. [28] have shown that there is a better correlation between the loss of compressive strength and the crater volume $\mathrm{Cv}$ compared to the 3D surface roughness criterion (Sa) when machining carbon/epoxy composite material made of unidirectional plies by conventional process. Moreover, in the work proposed by Saleem et al. [29,30], it was clearly observed that, although the specimens drilled by conventional process present the same Sa roughness to those drilled by abrasive water jet process, their endurances limits (tensile-tensile fatigue loading) are inferior by $15 \%$. In the context of repair application of multi-material structures composed metallic and composite parts, it can be interesting to use the same surface quality criterion. For these reasons, it has been decided to keep $\mathrm{Cv}$ as the surface quality criterion of this investigation. In addition, its definition, as detailed in section II.3.1., better fits with the material removal mechanisms (abrasive particle impact) and induced defects (craters) consecutive to AWJ machining.

\subsection{Post-cleaning material modifications}

It was found from the BSE image analysis that nearly $50 \%$ of the milled surface area is covered with embedded abrasive particles. This surface contamination can pose a threat to material integrity and efficient functioning of the machined component during service life. Hence it is necessary to get rid of this contamination caused by grit embedment. The most straight forward method for removing embedded abrasive grits is by cleaning with plain water jet similar to milling procedure, which was suggested by Hashish [18]. Post cleaning with water jet, it is important to inspect the surface for modifications and also analyse the contamination to check the effectiveness of the cleaning process. Hence, after cleaning, all the important parameters like milled depth, contamination and crater volume were analysed for few selected specimens and were compared with unclean specimens. Also post cleaning, the specimens were subjected to hardness and residual stress measurements which would have not been effectively possible prior to cleaning.

\subsubsection{Contamination}

The initial SEM observations revealed that the surface contamination was reduced after PWJ cleaning. Fig. 14a shows a BSE image of a specimen post PWJ cleaning. It is clearly seen that large abrasive particles have been removed from the machined surface. However, thought the cleaning process has reduced the rate of contamination, not all the embedded particles have been removed, especially in the case of deeply embedded particles (cf. Fig. 14b). It is also seen that the removal of large embedded abrasive particles generates a void. These newly created voids are similar to the craters in shape and size (cf. Fig. 14c) and hence can also be considered as crater defect. The BSE image analysis showed that the rate of contamination is reduced by almost 2.7 times.

Fig. 15 shows the evolution of the degree of contamination (both before and after cleaning) with respect to water pressure and milling

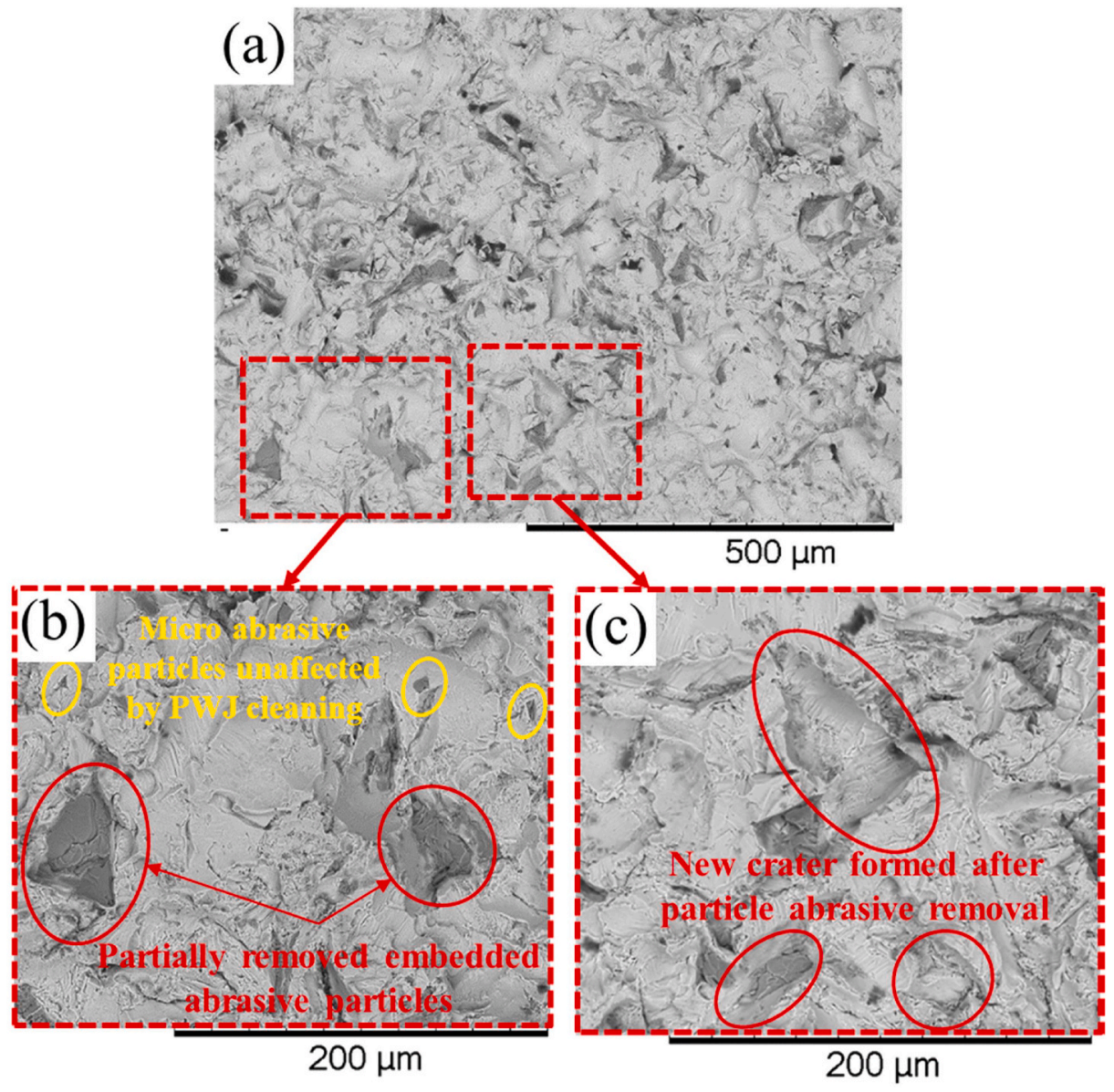

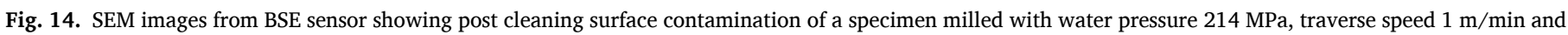

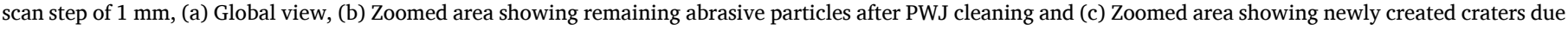
to PWJ cleaning. 


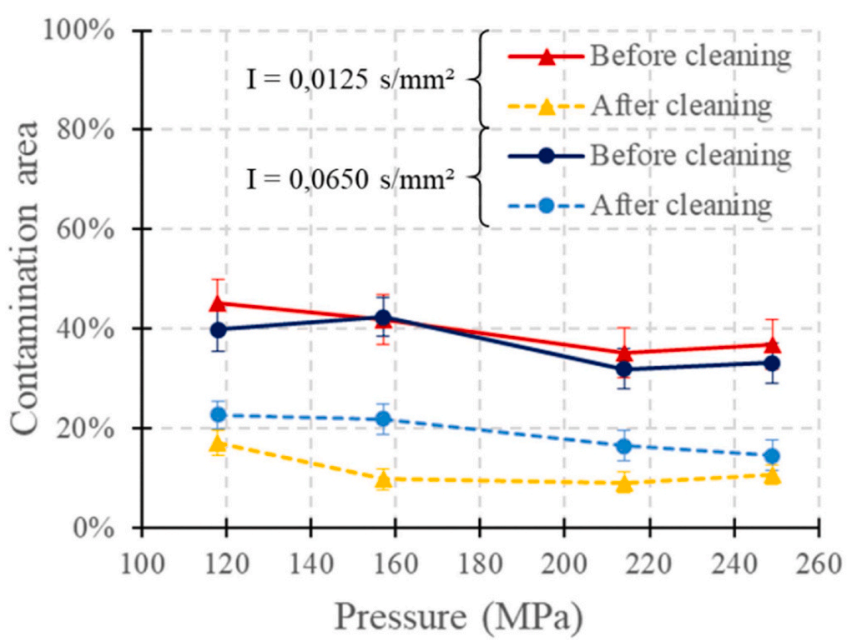

Fig. 15. Influence of the plain water jet cleaning process on the contaminated area.

intensity. It is seen that the post cleaning contamination rate slightly decreases with an increase in water pressure. As discussed earlier, at high water pressure, the secondary jet, which is mostly composed of water, possess higher energy and acts as a cleaning jet which removes loosely embedded abrasive particles. Hence, the initial contamination is slightly lower due to the moderate cleaning action of the secondary jet which have loosened some of the embedded abrasive particles, making it easier for the PWJ cleaning operation to remove the loosened particles. In addition, a clear reduction in the contamination rate is seen for specimens previously milled with low intensity. Indeed, a reduction of contamination from roughly $45 \%$ to approximately $10 \%$ and $20 \%$ is seen for specimens machined with intensities of 0.0125 and $0.0650 \mathrm{~s} / \mathrm{mm}^{2}$ respectively. In fact, at high intensity, the exposure time is high and hence higher number abrasive particles impact the workpiece surface. As the abrasive particles initially hitting the workpiece surface get embedded, new abrasive particles impact the already embedded particles. This forces the abrasive particles to embed deeper into the workpiece surface, making it more difficult for removal during PWJ cleaning. Also, when exposure time is high, the number of abrasive particles impacting the same workpiece area is high. Hence, after the initial embedment of a particle, the newly impacting abrasive particles plastically deform the area surrounding the already embedded particles and entrap them, reducing the chances of removal by PWJ cleaning.

\subsubsection{Machining depth}

The profile analysis of the specimens after PWJ cleaning show small

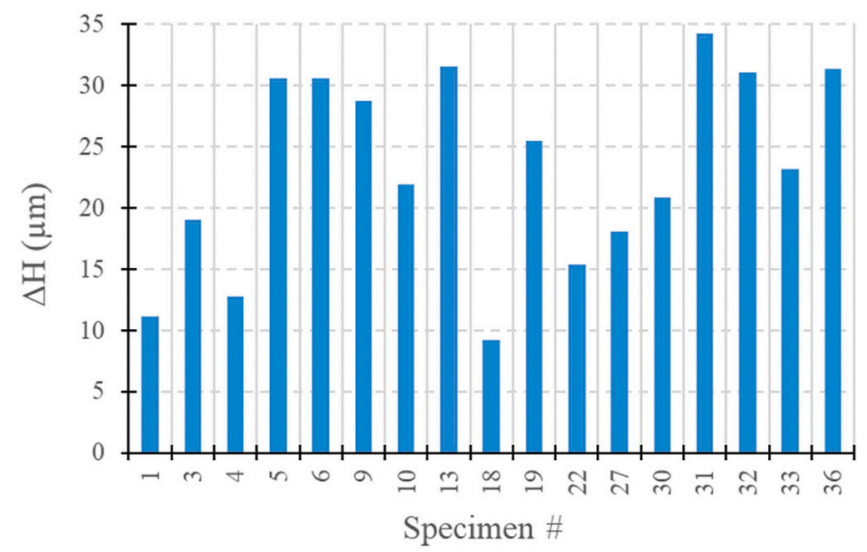

Fig. 16. Additional milling depth consecutive to the PWJ cleaning operation. increase in milled depth. Fig. 16indicates the change in milled depth of some of the PWJ cleaned specimens. It is observed that the milled depth is increased by few tens of micrometres. The increase in depth is mainly due to the formation of new craters following the removal of embedded abrasive particles and also elimination of burr along the crater wall sections of titanium surface (cf. Fig. 17a and b). This increase in depth is almost insignificant for specimens which have high milled depth. However, for specimens with minuscule milled depth the increase is quite important. For example, in case of specimen number 9, the post cleaning depth has increased almost by $300 \%$. However, it has to be noted that such small milling depths $(<10 \mu \mathrm{m})$ only represent surface preparation and hence, is out of context when milling operation is considered. Therefore, it can be concluded that PWJ cleaning operation can be performed on the AWJ milled Titanium alloy without considering any correction factors during AWJ milling for depth changes that may occur due to PWJ cleaning.

\subsubsection{Defects}

As for the milled depths, the changes in crater volume consecutive to the PWJ cleaning operation were also studied and quantified (cf. Fig. 18). It is seen that there is no specific trend in the change in crater volumes. During PWJ cleaning, two kinds of phenomenon may occur. Firstly, the plain water jet acts on embedded abrasive particles by pushing them out of the machined surface, creating a void similar in size and form as a crater created by AWJ milling (cf. Fig. 14). These newly formed craters will increase the $\mathrm{Cv}$ of the specimens. Secondly, the PWJ may remove thin burrs from the crater walls of titanium from the surface. Fig. 17a and $b$ shows the images of AWJ milled specimens with typical crater anatomy containing burr along the crater walls. These thin sections are removed during PWJ cleaning, leading to smoothening action which reduces the size of the craters, thereby decreasing the crater volume. Both these actions can randomly occur in combination. Hence, in some cases the Cv has increased after the PWJ cleaning operation and in some cases it has decreased. However, the change in $\mathrm{Cv}$ is below $10 \%$ for all the specimens and is hence insignificant.

\section{Conclusion}

This article presents the experimental study on abrasive water jet (AWJ) milling of Titanium alloy (Ti6Al4V) followed by Plain Water Jet (PWJ) cleaning. The influence of AWJ process parameters (viz. water pressure, jet traverse speed and scan step) on the material removal rate, quality of the textured surface and machining induced defects is presented. A particular focus has been made on the different types of erosion defects due to the abrasive particles impact. Machining induced defects in terms of contamination rate and craters size were quantified by measuring the degree of contamination (thanks to image processing technique) and the original indicator called "crater volume" respectively. Finally, a comparison of these features before and after PWJ cleaning has been performed. Based on this study, the following conclusions can be drawn:

- The milled depth is strongly influenced by water pressure, jet traverse speed and scan step. In addition, the milled depth is directly proportional to the water pressure whereas inversely proportional to the jet traverse speed and scan step. For example, for SS $=1 \mathrm{~mm}$ and $\mathrm{V}=2 \mathrm{~m} / \mathrm{min}$, an increase in water pressure from $118 \mathrm{MPa}$ to 249 MPa leads to an augmentation of the machining depth from $125 \mu \mathrm{m}$ to $438 \mu \mathrm{m}$.

- Milling intensity is a comprehensive parameter which combines both jet traverse speed and scan step. The milled depth increases with increasing intensity parameter. However, material removal rate (MRR) reveals critical saturation behaviour with respect to milling intensity parameter. In fact, for any milling intensity parameter used, MRR increases with increase in water pressure. 

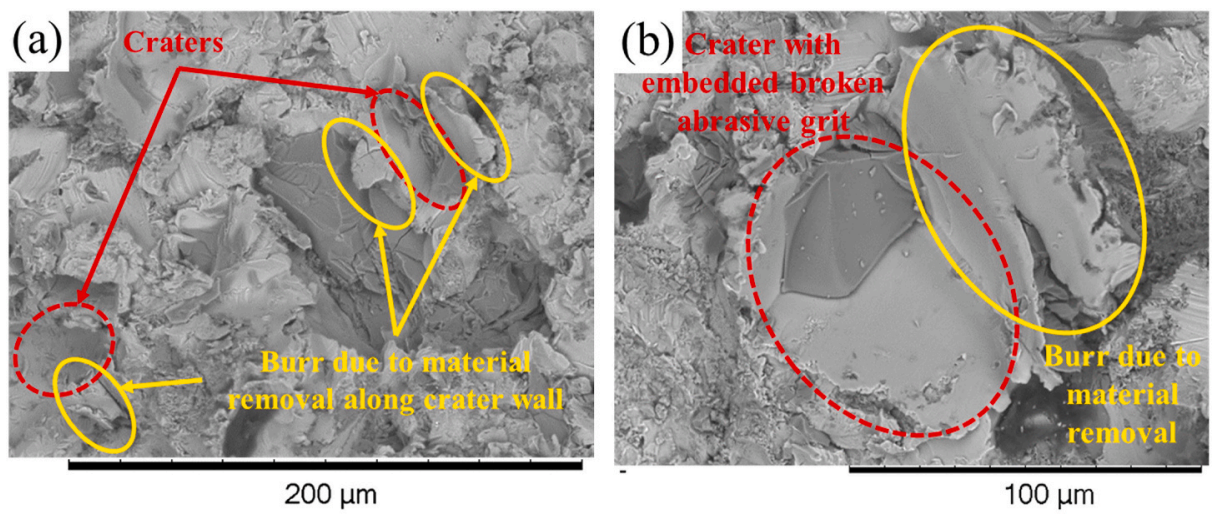

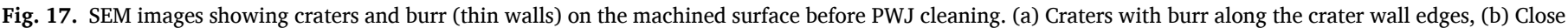
up image of the crater anatomy.

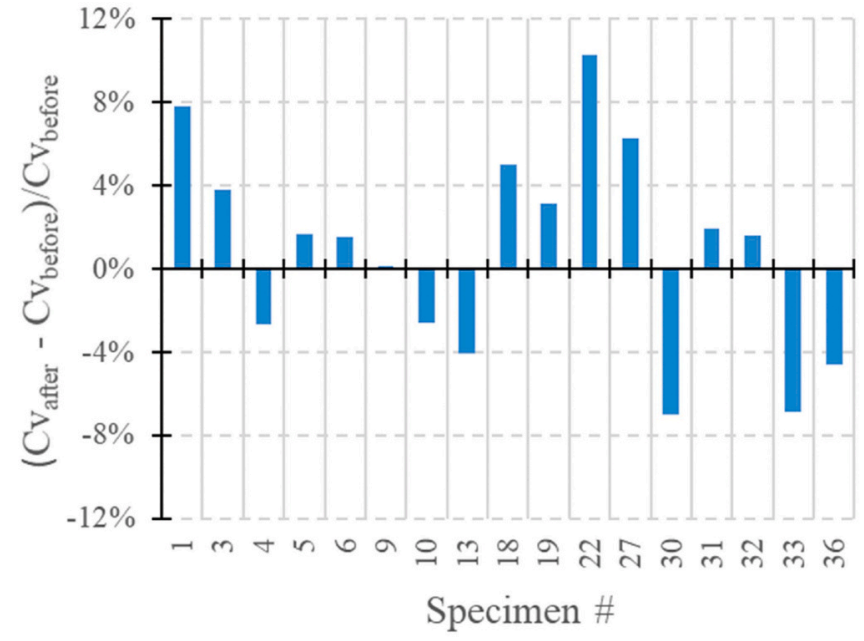

Fig. 18. Evolution of $\mathrm{Cv}$ consecutive to the PWJ cleaning process.

- The material removal by AWJ being produced by particle impact, two main types of erosion defects have been identified and quantified. Indeed, the erosion wear of titanium by AWJ machining induces a textured surface due composed of multiple craters, which depth and size are linked to the different types of material removal mechanisms of the process. The surface quality of the treated specimens has been quantified thanks to the innovative parameter called "crater volume". This indicator is linked to the kinetic energy of the particles (through the water pressure), as well as the duration of surface treatment (through "milling intensity"). In addition, due to the high velocity of the abrasive particles when impacting the target material, an important contamination of the machined surface by abrasive grit embedment has been noticed on all the specimens. The degree of surface contamination after AWJ milling has been estimated and is almost similar for all specimens (approximately 45\%), independently of the AWJ process parameters.

- Plain water jet cleaning is effective in reducing the contamination by $65 \%$ (polluted area around $10-20 \%$ post PWJ cleaning). As the remaining contamination rate is still important a greater pressure value has to be used in case of bonding application. However, according to the work conducted by Arola et al. [11], when milling of titanium alloy is conducted with plain water jet using high pressure (around $400 \mathrm{MPa}$ ) the level of residual stresses decreases. As the goal of the cleaning operation in the context of this study is to remove the contamination with few modifications in the material integrity (cf. section 2.2), using harsher cleaning conditions cannot be considered.
- Though PWJ cleaning operation post-AWJ machining induces an extra depth of cut between 10 and $35 \mu \mathrm{m}$, the modifications in surface quality are insignificant. This means that, when the specific case of repair application for adhesive bonding is considered, the AWJ milling parameters have to be chosen so few tens of microns of material remain for the PWJ cleaning operation, mandatory to obtain clean surfaces. In addition, the choice of these machining parameters is all the more important that is implies a specific texturing of the machined surface (defined in this study by $\mathrm{Cv}$ ), which will remain even after the cleaning operation.

\section{Declaration of competing interest}

The authors declare that they have no known competing financial interests or personal relationships that could have appeared to influence the work reported in this paper.

\section{Acknowledgments}

The authors want to sincerely thank Safran Aircraft Engines for its financial support and technical input.

\section{References}

[1] M. Hashish, An investigation of milling with abrasive-waterjets, J. Eng. Ind. 111 (1989) 158.

[2] M. Hashish, Controlled-depth Milling Techniques Using Abrasive Waterjets. Jet Cut. Technol, Mechanical Engineering Publications, London, 1994, pp. 449-461.

[3] V.H. Bui, P. Gilles, T. Sultan, G. Cohen, W. Rubio, A new cutting depth model with rapid calibration in abrasive water jet machining of titanium alloy, Int. J. Adv. Manuf. Technol. 93 (2017) 1499-1512.

[4] M. Kanthababu, R.M. Rajes, P.N. Emannuel, R. Gokul, R. Rammohan, Experimental investigations on pocket milling of Titanium alloy using abrasive water jet machining, FME Trans. 44 (2016) 133-138.

[5] J. Billingham, C.B. Miron, D.A. Axinte, M.C. Kong, Mathematical modelling of abrasive waterjet footprints for arbitrarily moving jets: Part II - overlapped single and multiple straight paths, Int. J. Mach. Tool Manufact. 68 (2013) 30-39.

[6] V.K. Pal, S.K. Choudhury, Surface characterization and machining of blind pockets on Ti6Al4V by abrasive water jet machining, Procedia Mater. Sci. 5 (2014) 1584-1592.

[7] G. Fowler, P.H. Shipway, I.R. Pashby, Abrasive water-jet controlled depth milling of Ti6Al4V alloy - an investigation of the role of jet-workpiece traverse speed and abrasive grit size on the characteristics of the milled material, J. Mater. Process. Technol. 161 (2005) 407-414.

[8] M.C. Kong, D.A. Axinte, W. Voice, Aspects of material removal mechanism in plain waterjet milling on gamma titanium aluminide, J. Mater. Process. Technol. 210 (2010) 573-584.

[9] L. Huang, J. Folkes, P. Kinnell, P.H. Shipway, Mechanisms of damage initiation in a titanium alloy subjected to water droplet impact during ultra-high pressure plain waterjet erosion, J. Mater. Process. Technol. 212 (2012) 1906-1915.

[10] G. Fowler, P.H. Shipway, I.R. Pashby, A technical note on grit embedment following abrasive water-jet milling of a titanium alloy, J. Mater. Process. Technol. 159 (2005) 356-368. 
[11] D. Arola, M.L. McCain, S. Kunaporn, M. Ramulu, Waterjet and abrasive waterjet surface treatment of titanium: a comparison of surface texture and residual stress, Wear 249 (2002) 943-950.

[12] P.H. Shipway, G. Fowler, I.R. Pashby, Characteristics of the surface of a titanium alloy following milling with abrasive waterjets, Wear 258 (2005) 123-132.

[13] D. Arola, C.L. Williams, Estimating the fatigue stress concentration factor of machined surfaces, Int. J. Fatig. 24 (2002) 923-930.

[14] M. Lieblich, S. Barriuso, J. Ibáñez, L. Ruiz-de-Lara, M. Díaz, J.L. Ocaña, et al., On the fatigue behavior of medical Ti6Al4V roughened by grit blasting and abrasiveless waterjet peening, J. Mech. Behav. Biomed. Mater. 63 (2016) 390-398.

[15] D. Arola, M.L. McCain, Abrasive waterjet peening: a new method of surface preparation for metal orthopedic implants, J. Biomed. Mater. Res. 53 (2000) 536-546.

[16] M.C. Kong, D.A. Axinte, W. Voice, An innovative method to perform maskless plain waterjet milling for pocket generation: a case study in Ti-based superalloys, Int. J. Mach. Tool Manufact. 51 (2011) 642-648.

[17] H.-T. Liu, Y. Hovanski, M.E. Dahl, Machining of aircraft titanium with abrasivewaterjets for fatigue critical applications, J. Pressure Vessel Technol. 134 (2012), 011405.

[18] M. Hashish, Method and Apparatus for Abrasive Water Jet Milling, 5704 824, 1998.

[19] L. Huang, P. Kinnell, P.H. Shipway, Parametric effects on grit embedment and surface morphology in an innovative hybrid waterjet cleaning process for alpha case removal from titanium alloys, Procedia CIRP 6 (2013) 594-599.

[20] A. Rivero, A. Alberdi, T. Artaza, L. Mendia, A. Lamikiz, Surface properties and fatigue failure analysis of alloy 718 surfaces milled by abrasive and plain waterjet, Int. J. Adv. Manuf. Technol. 94 (2018) 2929-2938.

[21] X. Sourd, R. Zitoune, L. Crouzeix, D. Lamouche, Controlled depth milling of hybrid aerospace grade materials using abrasive water jet - critical review and analysis, in: M.T. Hameed Sultan, A.I. Azmi, M.S.A. Majid, M.R.M. Jamir, N. Saba (Eds.), Mach. Mach. Fiber Reinf. Polym. Compos. Control., Springer, Singapore, 2021.

[22] A. Hejjaji, R. Zitoune, L. Crouzeix, F. Collombet, S. Le Roux, Impact of the abrasive water jet milling process on the damage and surface characteristics of CFRP composite, in: ECCM 2016 - Proceeding 17th Eur Conf Compos Mater, 2016.

[23] A. Hejjaji, R. Zitoune, L. Crouzeix, S. Le Roux, F. Collombet, Surface and machining induced damage characterization of abrasive water jet milled carbon/epoxy composite specimens and their impact on tensile behavior, Wear 376-377 (2017) 1356-1364.

[24] F. Cénac, R. Zitoune, F. Collombet, M. Deleris, Abrasive water-jet milling of aeronautic aluminum 2024-T3, Proc. Inst. Mech. Eng. Part L J Mater Des Appl (2013).

[25] M. Ramulu, S. Kunaporn, D. Arola, M. Hashish, J. Hopkins, Waterjet machining and peening of metals, Analyzer 122 (2000) 90-95.

[26] T. Sultan, P. Gilles, G. Cohen, F. Cénac, W. Rubio, Modeling incision profile in AWJM of Titanium alloys Ti6Al4V, Mec. Ind. 17 (2016) 403.

[27] D. Arola, A.E. Alade, W. Weber, Improving fatigue strength of metals using abrasive waterjet peening, Mach. Sci. Technol. 10 (2006) 197-218.

[28] N. Nguyen-Dinh, A. Hejjaji, R. Zitoune, C. Bouvet, M. Salem, New tool for reduction of harmful particulate dispersion and to improve machining quality when trimming carbon/epoxy composites, Compos Appl Sci Manuf (2020) 131.

[29] M. Saleem, L. Toubal, R. Zitoune, H. Bougherara, Investigating the effect of machining processes on the mechanical behavior of composite plates with circular holes, Compos Appl Sci Manuf 55 (2013) 169-177.

[30] M. Saleem, R. Zitoune, I. El Sawi, H. Bougherara, Role of the surface quality on the mechanical behavior of CFRP bolted composite joints, Int. J. Fatig. 80 (2015) $246-256$. 